\title{
ANALISIS KUALITAS BUTIR SOAL UJIAN AKHIR SEMESTER GASALMATA PELAJARAN PEMELIHARAAN SASIS DAN PEMINDAH TENAGA KENDARAAN RINGAN KELAS XI TKR DI SMK NEGERI 2 PRAYA TENGAH TAHUN AJARAN 2020/2021
}

\author{
Aulia Jazman Yazid *, Martubi \\ Fakultas Teknik, Universitas Negeri Yogyakarta \\ *Corresponding Author: jazmanyazid@gmail.com
}

\begin{abstract}
This study is aimed to know the quality of odd semester National Final Exam (UAS) question items of the subject The Chassis Maintenance and Light Vehicle Power Transfer at XI grade TKR at SMK Negeri 2 Praya Tengah in the academic year 2020/2021. The subjects of this study are XI grade students of Light Vehicle Engineering class at SMK Negeri 2 Praya Tengah. The technique of collecting data is documentation in order to get the data such as questions, answer keys and the students' answers. Question items are analyzed by anates program including the validity, reliability, difficulty level, distinguish power, and the deceitful effectiveness. The result of analyzing the question items of odd semester National Final Exam (UAS) of the subject The Chassis Maintenance and Light Vehicle Power Transfer at XI grade TKR at SMK Negeri 2 Praya Tengah in the academic year 2020/2021 based on the validity aspect is $37.5 \%$ questions are categorized valid and $62.5 \%$ questions are invalid. Based on the reliability aspect, it shows the value 0.51 which means the questions have low reliability. From the aspect of difficulty level, $42.5 \%$ questions are categorized difficult, $52.5 \%$ in the medium category and $5 \%$ are categorized easy. Based on distinguish power aspect, $25 \%$ is good, $25 \%$ is sufficient, $42.5 \%$ $\mathrm{bad}$, and $7.5 \%$ very bad. While from the deceitful effectiveness, 95\% questions are very good, $2.5 \%$ good, and $2.5 \%$ is good enough.
\end{abstract}

Key Words: item quality analysis, Light Vehicle Engineering, anates software

\begin{abstract}
Abstrak
Penelitian ini dilaksanakan bertujuan untuk mengetahui kualitas dari butir-butir soal UAS gasal Mata Pelajaran Pemeliharaan Sasis dan Pemindah Tenaga Kendaraan Ringan kelas XI TKR di SMK Negeri 2 Praya Tengah tahun ajaran 2020/2021. Penelitian ini adalah penelitian dengan subyek penelitiannya adalah siswa kelas XI Teknik Kendaraan Ringan di SMK Negeri 2 Praya Tengah. Teknik pengumpulan data secara dokumentasi agar mendapatkan data berupa soal, kunci jawaban dan juga jawaban dari peserta didik. Analisis butir soal menggunakan program anates meliputi validitas, reliabilitas, tingkat kesukaran, daya pembeda, dan efektifitas pengecoh. Hasil analisis butir soal UAS gasal mata pelajaran Pemeliharaan Sasis dan Pemindah Tenaga Kendaraan Ringan Kelas XI TKR di SMK Negeri 2 Praya Tengah tahun ajaran 2020/2021 jika dilihat dari aspek validitas 37,5\% soal dalam kategori valid dan 62,5\% soal tidak valid. Dari aspek reliabilitas menunjukkan nilai 0,51 dimana nilai tersebut menunjukkan soal memiliki reliabilitas rendah. Dari aspek tingkat kesukaran 42,5\% dengan kategori sukar, 52,5\% kategori sedang, dan 5\% mudah. Dari aspek daya pembeda 25\% soal baik, 25\% cukup, 42,5\% jelek, dan 7,5\% sangat jelek. Kemudian untuk efektifitas pengecoh 95\% soal sangat baik, $2,5 \%$ baik, dan $2,5 \%$ cukup baik.
\end{abstract}

Kata Kunci: Analisis Kualitas Butir Soal, Teknik Kendaraan Ringan, software anates 
36 Aulia Jazman Yazid \& Martubi

\section{PENDAHULUAN}

Satu dari sekian kebutuhan setiap masyarakat atau orang adalah pendidikan yang harus dimiliki setiap orangnya agar dapat mengembangkan potensi diri dan menambah wawasan serta menambah pengetahuan untuk dapat memenuhi kebutuhan-kebutuhan hidup. Pendidikan dapat memberikan sebuah pengalaman berharga sehingga nantinya mampu menghadapi berbagai permasalahan yang muncul pada setiap individunya. Seperti dalam KBBI, mengartikan Pendidikan ialah proses untuk mengubah perilaku dan sikap seseorang melalui bentuk pengajaran sehingga pendidikan dapat dikatakan mencetak individu yang ahli untuk diterapkan dalam kebutuhan masyarakat secara umum.

Saat proses belajar tentunya guru atau pendidik merumuskan dan membuat sebuah penilaian untuk menilai kesuksesan hasil dari proses pembelajaran. Penilaian yang baik merupakan sebuah upaya dalam meningkatkan kualitas dalam bidang pendidikan. Penilaian ditinjau dari Peraturan Menteri Pendidikan dan Kebudayaan Indonesia Nomor 34 Tahun 2018 tentang Standar Penilaian Pendidikan menyatakan bahwa penilaian adalah proses pengumpulan dan pengolahan informasi untuk mendeskripsikan capaian belajar dari peserta didik.

Salah satu syarat dari penilaian dapat dikatakan baik dan berhasil apabila soal tes dimana instrument soalnya memiliki kualitas yang baik pula. Seperti menurut Suharsimi (2012: 57) menyatakan bahwa validitas, objektivitas, ekonomis, reliabilitas, dan praktikabilitas harus terpenuhi sebagai syarat apabila tes ingin dikategorikan menjadi alat ukur yang baik. Ketika guru membuat dan menyusun soal, sudah harus sepenuhnya serius saat membuat dan juga menyusun dari proses perencanaan interaksi pembelajaran. Soal ataupun tes merupakan instrumen di dalam penilaian yang dibentuk atau dibuat oleh tenaga pendidik. Akan tetapi, soal soal yang dibuat dan juga dipakai itu masih menjadi tanda tanya sudahkah atau belum termasuk di dalam kategori soal yang berkualitas baik ataupun belum. Berdasar hal tersebut guru sejatinya harus selalu memperhatikan instrument tesnya apakah kategorinya memiliki kualitas yang baik ataupun belum.

SMK Negeri 2 Praya Tengah ialah satu dari sekian SMK rujukan di Praya Tengah dimana pada SMK ini dapat dikatakan masih belum memiliki kriteria dalam konteks evaluasi. Guru sebagai seorang pendidik, dalam pembuatan soal masih belum memperhatikan kriteria atau aspek-aspek pembuatan soal secara baik. Akibatnya, soal-soal yang dibuat tentu dianggap memiliki kualitas yang baik padahal masih belum diketahui apakah memang baik ataupun tidak. Kemudian, tidak jarang ditemukan bahwa soal tahun sebelumnya masih dipakai lagi untuk tahun-tahun selanjutnya.

Sudah seharusnya dalam teknik penyusunan soal diperhatikan dengan baik oleh setiap guru pendidik dengan maksud memiliki pengembangan pada teknik penyusunan soalnya. 
Ketika teknik penyusunan soal dilakukan maksimal maka dapat ditemukan pula keunggulan serta kelemahan dari soal tersebut. Keunggulan dan kelemahan soal tersebut yang nantinya akan sebagai bantuan bagi seorang guru pendidik untuk terus meningkatkan penyusunan soal secara baik.

Pada SMKN 2 Praya Tengah kompetensi keahlian Teknik Kendaraan Ringan, siswa memiliki nilai rata-rata selama satu semester di mata pelajaran atau mata diklat PSPT kelas XI hanya berada sedikit di atas KKM. Menurut guru mata pelajaran PSPT Kelas XI kompetensi keahlian TKR di SMK Negeri 2 Praya Tengah bahwa rata-rata nilai ujian akhir yang didapatkan oleh siswa tidak jauh dari KKM karena penyebabnya beberapa hal. Adapun satu penyebabnya adalah tidak dilakukannya pengawasan secara ketat pada soal yang. Dikarenakan hal tersebut maka guru menganggap soal tersebut masih relevan untuk digunakan. Hal ini membuat guru tidak melaksanakan untuk menganalisis kualitas dari butir soal tersebut sehingga soal-soal itu kualitasnya belum dapat untuk diketahui. Oleh karena itu diperlukanlah analisis butir soal dimana melalui analisis dari butir-butir soal guru tentunya bisa memperoleh bantuan informasi terkait kualitas dari soal yang dipakai untuk menguji peserta didik.

Analisis butir soal tentunya memiliki bagian-bagian yang akan dipakai dalam proses menganalisis soal yang mana diantaranya adalah analisis validitas, reliabilitas, tingkat kesukaran, daya pembeda, dan efektivitas pengecoh. Menganalisis soal dari segi validitas dan juga reliabilitas bertujuan untuk mengetahui sekaligus mengkaji dari layak atau tidaknya sebuah soal untuk mendapat ketentuan aspek manakah yang wajib diukur dan konsistensi dari soal tersebut. Tingkat kesukaran soal yaitu bertujuan untuk mengetahui soal dari aspek tingkat kesulitannya, dengan hal tersebut maka bisa dikethui soal manakah yang dikategorikan mudah, sedang maupun sukar. Kemudian dalam menganalisis daya pembeda artinya ialah untuk mengetahui soal dari aspek bisa tidaknya soal tersebut untuk membuat perbedaan antara siswa yang tergolong prestasinya tinggi atau tidak dan fungsi dari pengecoh ialah seberapa tepat pilihan jawaban itu digunakan sebagai pengecoh.

Upaya yang dilakukan agar mengetahui kualitas dari soal ialah dengan menganalisis butir soal yang mana hal tersebut haruslah dilakukan. Analisis kualitas butir soal adalah salah satu pertimbangan dengan maksud mengetahui kualitas secara ril peserta didik dan dapat sebagai penentu kualitas pendidikan dalam kedepannya. Berdasar beberapa masalah yang telah dijelaskan dan diuraikan, peneliti menganggap bahwa analisis butir soal harus dikerjakan dengan maksud untuk dapat memperoleh informasi dari kualitas dari berbagai tes yang diberikan dimana kedepannya setelah dilakukan analisis maka akan digunakan sebagai pertimbangan saat melakukan evaluasi dalam penyusunan dan pembuatan soal. 


\section{METODE}

Penelitian ini termasuk penelitian deskriptif dan menggunakan pendekatan kuantitatif dengan maksud data analisis tersebut berupa deskripsi gejala-gejala yang diamati, yang berbentuk angka-angka atau koefisien antar variable. Penelitian ini dilaksanakan di SMK Negeri 2 Praya Tengah, yang beralamat di Jalan Pejanggik No.09 Praya Tengah, Lombok Tengah, NTB. Adapun untuk pelaksanaan penelitian, pada bulan Desember 2020.

Subyek dalam penelitian ini adalah semua siswa kelas XI Kompetensi Keahlian Teknik Kendaraan Ringan tahun ajaran 2020/2021 di SMK Negeri 2 Praya Tengah, yaitu Kelas XI TKR 1 dan XI TKR 2. Kemudian obyeknya ialah semua dokumen yang terdiri atas soal UAS Gasal PSPT, kunci jawaban, dan lembar jawaban siswa.

Metode dokumentasi merupakan cara yang dipakai untuk melakukan pengumpulan data.Instrumen pada penelitian ini adalah daftar centang atau ceklist berupa form pengumpul data dimana untuk mengumpulkan informasi sekaligus mendapat data penelitian berupa nama siswa, soal, kunci jawaban dan lembar jawaban Ujian Akhir Semester Gasal Mata Pelajaran PSPT Kelas XI TKR di SMK Negeri 2 Praya Tengah dalam bentuk soft file. Teknik analisis data dalam penelitian ini menggunakan cara kuantitatif yang terdiri atas validitas, reliabilitas, tingkat kesukaran, efektifitas pengecoh, dan daya pembeda.

\section{HASIL DAN PEMBAHASAN}

\section{Validitas}

Berdasar empat puluh butir soal yang telah dilakukan analisis segi validitasnya, diketahui bahwa $37,5 \%$ atau lima belas soal dengan kategori valid, dan 62,5\% atau 35 soal dengan kategori tidak valid. Kemudian apabila ke empat puluh soal tersebut didistribusikan sesuai dengan indeks validitas, maka pendistribusiannya dapat dilihat seperti berikut ini :

Tabel 1. Distribusi Butir Soal Sesuai Indeks Validitas

\begin{tabular}{clcc}
\hline $\begin{array}{c}\text { Indeks } \\
\text { Validitas }\end{array}$ & \multicolumn{1}{c}{ Nomor Soal } & Jumlah & Persentase \\
\hline Valid & $5,6,8,12,19,21,22,24,27,33,35,37,38,39,40$ & & \\
Tidak Valid & $\begin{array}{l}1,2,3,4,7,9,10,11,13,14,15,16,17,18,20,23,25,26,28,29 \\
\end{array}$ & 25 & $37,5 \%$ \\
& $, 30,31,32,34,36$ & & \\
\hline
\end{tabular}




\section{Distribusi Indeks \\ Validitas}

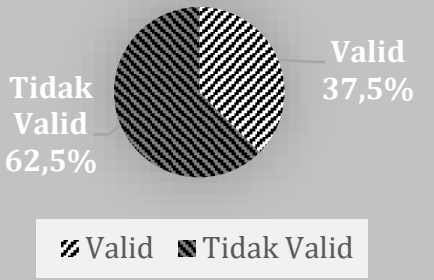

Gambar 1. Distribusi Indeks Validitas

Rumus korelasi point biserial dapat menghitung nilai dari Validitas item yang mana proses perhitungan tersebut di support dengan menggunakan software Anates. Hasil perhitungan tersebut selanjutnya dibandingan dengan menggunakan $r_{\text {tabel }}$ dimana taraf signifikannya sebesar 5\%. Kemudian dapat diketahui valid atau tidak validnya. Soal yang valid sudah memiliki ketepatan yang baik dalam mengukur dan sebaliknya jika tidak valid maka ketepatannya belum baik dan perlu dilakukan evaluasi kembali.

Tindak lanjut dari hal ini yang bisa untuk dilakukan adalah soal yang telah masuk dalam kategori valid (memiliki point 1) dapat digunakan kembali pada tes-tes obyektif selanjutnya kemudian soal yang masih berkategori tidak valid (memiliki point (0) maka dapat untuk direvisi apabila tahun selanjutnya akan digunakan kembali.

\section{Reliabilitas}

Diketahui bahwa reliabilitas soal adalah sejumlah 0,51 . Hasil reliabilitas soal tes pilihan ganda mata pelajaran Pemeliharaan Sasis dan Pemindah Tenaga Kendaraan Ringan tersebut dapat dikatakan reliabilitas yang rendah dikarenakan reliabilitasnya memiliki nilai 0,51 dimana kurang dari 0,7 .

\section{Tingkat Kesukaran}

Berdasar empat puluh butir soal yang telah dilakukan analisis segi tingkat kesukarannya, diketahui bahwa terdapat dua butir soal berkategori mudah, 21 butir soal berkategori sedang dan tujuh belas butir soal berkategori sukar Kemudian hasil dari distribusi soal berdasar tingkat kesukaran adalah seperti di bawah ini.

Tabel 2. Distribusi dari Butir Soal Berdasar Tingkat Kesukaran

\begin{tabular}{cccc}
\hline Kategori & Jumlah & Persentase & Nomor Soal \\
\hline Mudah & 2 & $5 \%$ & 1,2 \\
Sedang & 21 & $52,5 \%$ & $3,4,6,8,10,12,1315,17,19,21,22,23,26,29,33,34,35,37,39,40$ \\
Sukar & 17 & $42,5 \%$ & $5,7,9,11,14,16,18,20,24,25,27,28,30,31,32,36,38$ \\
\hline
\end{tabular}




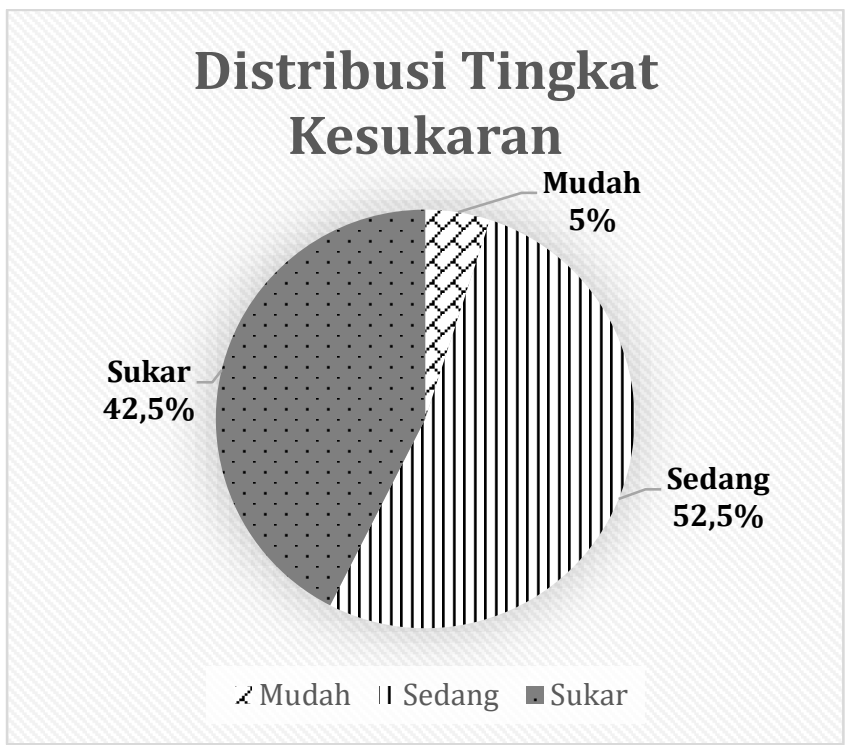

Gambar 2. Distribusi Tingkat Kesukaran

Menurut Martubi (2004), klasifikasi dari tingkat kesukaran dibagi menjadi 3 bagian, yaitu sukar, sedang, dan mudah. Kemudian Suharsimi Arikunto (2013:222) memaparkan bahwasanya soal yang tergolong baik merupakan soal yang mana tidak begitu sukar maupun tidak terlalu mudah. Berdasar hal tersebut nantinya soal yang dengan tingkat kesukaran sedang akan mendapat point 1 dan point 0 untuk kategori sukar dan mudah sebagai tindak lanjutnya.

\section{Daya Pembeda}

Berdasar empat puluh butir soal yang telah dilakukan analisis segi daya pembedanya, diketahui bahwasanya sejumlah tiga soal kategori sangat jelek, tujuh belas soal kategori jelek, sepuluh soal dikelompok/kategori cukup, dan sepuluh soal dikelompok/kategori baik. Berikut penyajian tabel dan pie chart nya.

Tabel 3. Distribusi Butir Soal Berdasarkan Daya Pembeda

\begin{tabular}{ccc}
\hline Kategori & Jumlah Soal & Persentase \\
\hline Sangat Jelek & 3 & $7,5 \%$ \\
Jelek & 17 & $42,5 \%$ \\
Cukup & 10 & $25 \%$ \\
Baik & 10 & $25 \%$ \\
\hline
\end{tabular}




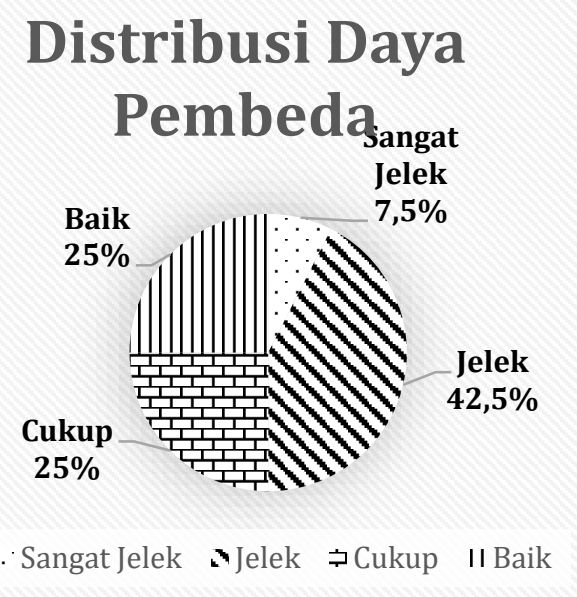

Gambar 3. Distribusi Daya Pembeda

Untuk soal dikatakan memadai maka daya pembedanya berkategori cukup dan baik. Kemudian soal yang tidak memadai maka daya pembedanya berkategori jelek dan sangat jelek. Soal yang memadai dapat digunakan kembali dikarenakan soal terkait memiliki kemampuan dalam membagi siswa yaitu antara siswa yang belum paham terkait materi dan siswa yang sudah paham terkait materi. Kemudian soal yang tidak memadai sebaiknya dibuang dikarenakan belum bisa membagi siswa yaitu antara siswa yang belum paham terkait materi dan siswa yang sudah paham terkait materi. Sehingga daya pembeda berkategori cukup dan baik memiliki point 1 dan point 0 untuk daya pembeda jelek dan sangat jelek.

Beberapa hal dapat ditindak lanjuti, yaitu antara lain adalah butir soal yang mempunyai kategori daya beda yang baik bisadimasukkan dalam kumpulan (bank) soal supaya selanjutnya bisa dipakai kembali, selanjutnya soal yang memiliki kategori daya beda yang cukup sebaiknya dilakukan revisi lagi agar menghasilkan soal berdaya beda yang bagus. Lalu terkait butir soal yang jelek alangkah baiknya direvisi lagi ataupun dapat dibuang apabila tidak digunakan dan terakhir bagi butir-butir soal yang berkategori daya beda yang sangat jelek alangkah sebaiknya untuk dibuang.

\section{Efektifitas Pengecoh}

Berdasar empat puluh butir soal yang telah dilakukan analisis segi daya pembedanya, diketahui bahwasanya terdapat 38 soal dengan kategori sangat baik dari segi efektifitas pengecohnya, kemudian satu soal berkategori baik, dan satu soal dengan kategori cukup baik. Di bawah ini merupakan distribusi dari efektivitas pengecoh dari butir soal. 
Tabel 4. Distribusi Efektifitas Pengecoh

\begin{tabular}{ccccc}
\hline No. & Kategori & No.Soal & Jumlah & Persentase \\
\hline 1 & Sangat Baik & $3,4,5,6,7,8,9,10,11,12,13,14$, & 38 & $95 \%$ \\
& & $15,16,17,18,19,20,21,22,23$, & & \\
& & $24,25,26,27,28,29,30,31,32$ & & \\
2 & Baik & $33,34,35,36,37,38,39,40$ & & \\
3 & Cukup Baik & 2 & 1 & $2,5 \%$ \\
4 & Kurang Baik & 1 & 1 & $2,5 \%$ \\
\hline
\end{tabular}

\section{Distribusi Efektifitas \\ Pengecoh}
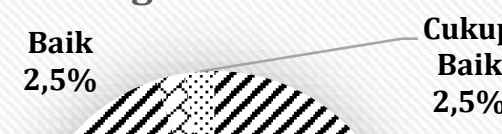

, $5 \%$

Gambar 4. Distribusi Efektifitas Pengecoh

Kategori sangat baik, baik, dan cukup memiliki point 1 dan point 0 untuk kategori yang kurang baik sebagai tindak lanjutnya. Soal ini dari segi efektifitas pengecoh sudah baik secara keseluruhan. Soal tersebut dapat digunakan dan harus dipertahankan untuk tes berikutnya.

\section{SIMPULAN}

Berdasar hasil penelitian dan pembahasan mengenai analisis butir soal Ujian Akhir Semester Gasal Mata Pelajaran Pemeliharaan Sasis dan Pemindah Tenaga Kendaraan Ringan Kelas XI TKR di SMK Negeri 2 Praya Tengah Tahun Ajaran 2020/2021 yang terdiri atas segi validitas, reliabilitas, tingkat kesukaran, daya pembeda, dan efektifitas pengecoh, lalu diambil kesimpulan yaitu :

1. Dari segi validitas, hasil dari analisis butir soal menunjukkan bahwa sejumlah lima belas soal $(37,5 \%)$ valid dan sejumlah 25 soal $(62,5 \%)$ tidak valid.

2. Segi reliabilitasnya, hasil dari analisis butir soal menunjukkan bahwa nilai reliabilitas soal sejumlah 0,51 dimana nilai tersebut menunjukkan reliabilitas rendah.

3. Dari segi tingkat kesukaran, hasil dari analisis butir soal menunjukkan bahwa dua soal (5\%) berkategori mudah, 21 soal $(52,5 \%)$ berkategori sedang, dan tujuh belas soal $(42,5 \%)$ berkategori sukar. 
4. Dari segi daya pembeda, hasil dari analisis butir soal menunjukkan bahwa tiga soal $(7,5 \%)$ berkategori sangat jelek, tujuh belas soal $(42,5 \%)$ berkategori jelek, sepuluh soal $(25 \%)$ berkategori cukup, dan sepuluh soal (25\%) dalam kategori yang baik.

5. Dari segi efektifitas pengecoh, hasil dari analisis butir soal menunjukkan bahwa 38 soal $(95 \%)$ berkategori sangat baik, satu soal $(2,5 \%)$ berkategori baik, dan satu soal $(2,5 \%)$ berkategori cukup baik.

\section{DAFTAR PUSTAKA}

Anas Sudijono. (2012). Pengantar Evaluasi Pendidikan. Jakarta: PT. Raja Grafindo Persada

Arifin, Zainal. 2016. Evaluasi Pembelajaran (Prinsip, Teknik, dan Prosedur), Cetakan Kedelapan, Jakarta: Rosda Karya

Hamalik, Oemar. (2008). Proses Belajar Mengajar. Jakarta: Sinar Grafika

Kemendikbud. (2018). Permendikbud No 34 Tentang Standar Penilaian Pendidikan. Jakarta: Kemendikbud

Martubi. (2004). Evaluasi Pembelajaran Teori (Kognitif)

Nana Sudjana. (2011). Penilaian Hasil Proses Belajar Mengajar, Bandung : PT Remaja Rosdakarya

Pendidikan. Dalam Kamus Besar Bahasa Indonesia (KBBI) Online. Diakses melalui https://kbbi.kemdikbud.go.id/entri/pendidikan, 25 Januari 2021

Purnama, E.R.D. and Martubi, M., (2017). ANALISIS BUTIR SOAL UJIAN AKHIR SEMESTER MATAPELAJARAN PEMELIHARAAN SISTEM KELISTRIKAN OTOMOTIF DAN MESIN OTOMOTIF. E-Jurnal Pendidikan Teknik Otomotif$S 1,21(1)$

Suharsimi Arikunto. (2012). Dasar-Dasar Evaluasi Pendidikan. Jakarta: Bumi Aksara

Undang-Undang Nomor 20 Tahun 2003 tentang Sistem Pendidikan Nasional, Jakarta: Fokus Media

Windarto, F. and Martubi, M., (2017). ANALISIS BUTIR SOAL UJIAN AKHIR SEMESTER GENAP MATA DIKLAT DASAR-DASAR MESIN. E-Jurnal Pendidikan Teknik Otomotif-S1, 19(2). 
44 Aulia Jazman Yazid \& Martubi 